\title{
The Role of Mean Platelet Volume on Distinction of Submucosal Myomas from Other Etiologies in Increased Endometrial Thickness
}

\author{
Kerem Doğa SEÇKİN¹, Mehmet Fatih KARSLI², Burak YÜCEL ${ }^{1}$ Elif AKKAŞ YILMAZ², Murat ÖZ³, Deniz BALSAK4, \\ Hüseyin KIYAK ${ }^{1}$, Gökhan YILDIRIM1
}

Istanbul, Turkey

\begin{abstract}
OBJECTIVE: The aim of the study was to determine whether it is possible to differentiate submucosal fibroids before interventional procedures based on mean platelet volume (MPV), in reproductive-age patients presenting with endometrial thickening and abnormal uterine bleeding.

STUDY DESIGN: This study included 581 reproductive-age women who underwent diagnostic procedures (curettage or operative hysteroscopy) and were subsequently divided into two groups based on clinico-pathological findings. The first group included those with benign endometrial pathology (control group, $n=438)$, and the second group consisted of those with submucosal leiomyomas $(n=143)$. The demographic characteristics and complete blood count (CBC) data of these patients were collected retrospectively, and comparisons were made between groups.

RESULTS: No statistically significant difference was found between the groups according to demographic features and CBC parameters such as hemoglobin levels and white blood count $(p>0,05)$. Platelet counts were significantly higher and MPV values were significantly lower in submucosal leiomyoma patients compared with the control subjects $(p<0,05)$.

CONCLUSIONS: MPV may be a useful predictive marker when differentiating submucosal leiomyoma from other benign causes of abnormal uterine bleeding. The ability to predict the possibility of the presence of submucosal leiomyoma before surgery can assist in determining the most appropriate type of invasive procedure.
\end{abstract}

Keywords: Mean platelet volume, Endometrial thickness, Submucosal myoma

Gynecol Obstet Reprod Med 2016;22:32-35

\section{Introduction}

Abnormal uterine bleeding (AUB) is one of the most common reason of outpatient gynecologic visits and a very frequent gynecological complaint in the reproductive age group. It is referred as excessive bleeding at any time or bleeding outside the normal menstrual cycle and constitutes a major clinical indication for hysterectomy. ${ }^{1}$ Diagnostic procedures included transvaginal sonography, pelvic examination and a detailed medical history. ${ }^{2}$ In patients 35 years and older presenting with endometrial thickening $\geq 12 \mathrm{~mm}$, en-

\footnotetext{
${ }^{I}$ Department of Obstetrics and Gynecology, Kanuni Sultan Suleyman Training and Research Hospital, Istanbul

2 Department of Obstetrics and Gynaecology, Sami Ulus Women and Children Health Training and Research Hospital, Ankara

${ }^{3}$ Department of Obstetrics and Gynaecology, Zekai Tahir Burak Womens' Health and Research Hospital, Ankara

${ }^{4}$ Department of Obstetrics and Gynaecology, Halic University, Istanbul

Address of Correspondence: Kerem Doğa Seçkin

Kanuni Sultan Süleyman

Education and Research Hospital,

Obstetrics and Gynecology Department, Istanbul, Turkey

doga_seckin@hotmail.com

Submitted for Publication

04.01 .2016

Accepted for Publication:

16.02.2016
}

dometrial biopsy is the most effective way to confirm the pathological diagnosis. ${ }^{3}$

In recent years hysteroscopic evaluation is the gold standard in AUB as it gives the chance of direct visualization of the endometrial pathologies and guided biopsy of any local lesion. ${ }^{4-6}$ But in terms of accessibility and cost effectiveness endometrial curettage is still preferred by clinicians as the initial diagnostic tool.

The diagnostic value of complete blood count such as, mean platelet volume (MPV), neutrophil to lymphocyte ratio (NLR) and platelet to lymphocyte ratio (PLR) parameters has been the subject of many studies in gynecology and gynecological oncology. ${ }^{7,8}$ In the case of uterine fibroids or leiomyomas, the increased expression of erythropoietin (EPO) and platelet-derived growth factor A (PDGF-A) within the growths may influence $\mathrm{CBC}$ parameters in a diagnostically significant manner. This is because EPO and PDGF-A both promote the development of uterine smooth muscle cells, thereby promoting growth of the leiomyoma and release of platelets from the bone marrow and thus eliciting a decrease in mean platelet volume (MPV). ${ }^{9,10}$

The aim of this study was to investigate the diagnostic value of platelet counts and MPV data in distinguishing the 
presence of submucosal leiomyomas. Such information is useful in the selection or planning of invasive procedures, such as hysteroscopy or curettage, among patients who have increased endometrial thickness and abnormal uterine bleeding.

\section{Material and Method}

This retrospective study was based on the review of medical files from 6,278 patients presenting with menstrual irregularities who then underwent diagnostic procedures at the gynecology clinic of a tertiary referral hospital. Written informed consent was obtained from all participants. The protocol was approved by the Hospital and the Ethics Committee of the Kanuni Sultan Süleyman Training and Research Hospital in accordance with the Declaration of Helsinki. The files of patients were evaluated and the information about age, gravida, parity, body mass index, complete blood count and pathology parameters were revealed. Curettage applied by carmen cannula was used as a diagnostic approach. Operative hysteroscopy was carried out using a $5 \mathrm{~mm}$ Karl-Storz optics. After expanding the uterine cavity by infusion of saline, hysteroscopically guided biopsies were taken with $5 \mathrm{~F}$ semi-rigid biopsy forceps. Patients with systemic disease (hepatic, renal, cardiac), patients with a history of drug use (anticoagulants, nonsteroidal anti-inflammatory drugs, oral contraceptives) or anemia and malignancy that can affect platelet count and MPV values were excluded. The pathology findings showed that 438 patients showed benign endometrial pathology (endometrial thickening due to the effects of estrogen/progesterone, chronic endometritis); these individuals were designated as group 1 (control). In contrast, 143 patients had submucosal fibroid(s) and were designated as group 2. The groups were compared according to whole blood parameters. Because it is difficult to distinguish endometrial polyps from submucosal fibroids due to their polypoid appearance, individuals with endometrial polyps were not included in the control group.

Statistical analyzes were performed using SPSS for Windows 15.0 computer software (Statistical Package for Social Sciences, Chicago, IL, USA). Parameters were ex- pressed as mean and standard deviation. Independent sample ttest was used to compare groups in terms of study parameters. ROC analyzes were performed to assess the diagnostic accuracy and to determine the optimal cut-off value of MPV. P values less than 0.05 were considered statistically significant.

\section{Results}

The control group included those with benign endometrial pathology (Group 1, n=438), and the second group consisted of those with submucosal leiomyomas (Group 2, n=143). The groups were similar according to demographic characteristics such as age, gravida, parity, body mass index and complete blood count parameters such as hemoglobin levels and white blood count ( $p>0,05)$. However, platelet counts were significantly higher and MPV values significantly lower in group 2 patients compared with group 1 control subjects $(p=0,001)$ (Table I). In the ROC curve analysis of MPV data, a cut-off value of 8.15 was identified, and the area under the curve (AUC) was found to be 0.611 . Sensitivity, specificity, positive predictive value and negative predictive values were found to be $71 \%, 61 \%, 67 \%, 65 \%$, respectively. The analysis of ROC curve was shown in Figure 1.

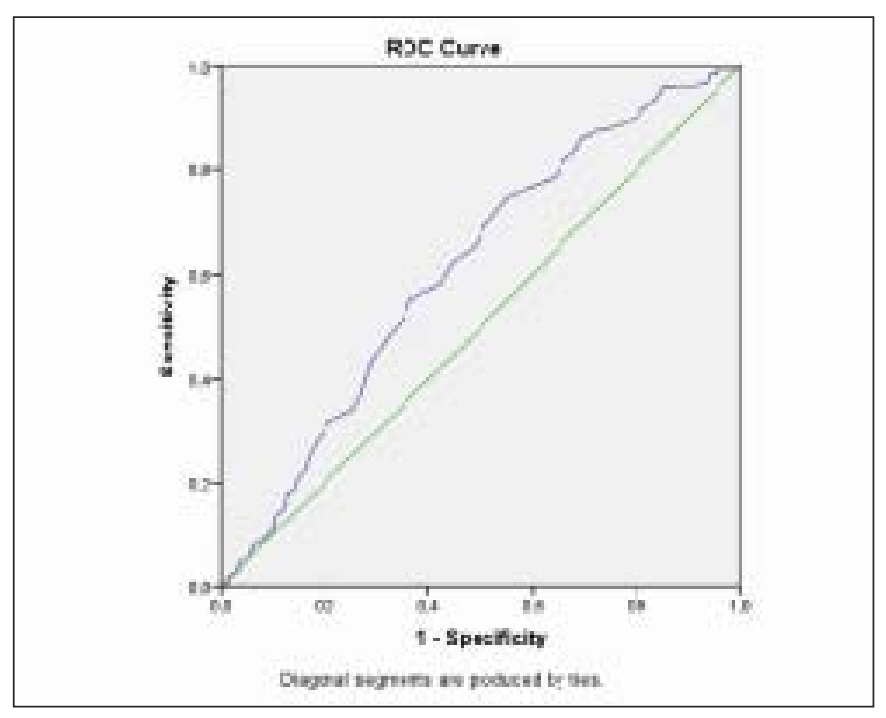

Figure 1: ROC curve analysis of Mean Platelet Volume

Table 1: Comparison of demographic features and complete blood count parameters between groups

\begin{tabular}{|c|c|c|c|}
\hline & $\begin{array}{c}\text { Control group } \\
\text { Group } 1 \\
(\mathrm{n}: 438) \text { Mean } \pm S D\end{array}$ & $\begin{array}{c}\text { Submucosal myoma } \\
\text { Group } 2 \\
\text { (n:143) Mean } \pm \text { SD }\end{array}$ & $\begin{array}{c}p \\
\text { value }\end{array}$ \\
\hline Age (years) & $42.24 \pm 6.89$ & $43.21 \pm 6.69$ & NS \\
\hline Gravidity & $2.5 \pm 1.3$ & $2.3 \pm 1.1$ & NS \\
\hline Parity & $1.1 \pm 0.8$ & $0.9 \pm 0.6$ & NS \\
\hline Body mass index $\left(\mathrm{kg} / \mathrm{m}^{2}\right)$ & $23.63 \pm 4.17$ & $24.93 \pm 3.31$ & NS \\
\hline Hemoglobin (gr/dL) & $11.2 \pm 1.22$ & $11.4 \pm 1.28$ & NS \\
\hline White blood cell count $\left(/ \mathrm{cm}^{3}\right)$ & $6.9 \pm 1.98$ & $7.7 \pm 2.57$ & NS \\
\hline Platelet count $\left(/ \mathrm{cm}^{3}\right)$ & $269.4 \pm 70.2$ & $281.8 \pm 69.3$ & 0.001 \\
\hline Mean platelet volume & $8.51 \pm 1.36$ & $8.02 \pm 1.55$ & 0.001 \\
\hline
\end{tabular}




\section{Discussion}

Myoma uteri is considered to be the most common uterine pathology in reproductive age women. ${ }^{11}$ Specifically, we found that platelet counts are higher and MPV values are lower among patients with submucosal fibroids compared with patients with endometrial thickening due to other causes. These results are consistent with previous studies showing that increased EPO secretion from leiomyomas promotes the release of precursor materials from the bone marrow. In addition, Asano et al. demonstrated that leiomyoma-derived EPO promotes the acceleration of tumor growth. ${ }^{12}$ Wolf et al. and McDonald et al. showed a significant increase in platelet production in animals receiving EPO. ${ }^{13,14}$ It has also shown in another study that uterine fibroids secrete PDGF-C, which subsequently promotes the growth of smooth muscle cells of the uterus and uterine fibroids. ${ }^{10}$ In addition, PDGF-C promotes platelet release from the bone marrow. ${ }^{9}$ Thus, as such reasons may influence the platelet counts and MPV levels in patients with submucosal fibroids, both platelet count and MPV data collected during the course of standard $\mathrm{CBC}$ analysis may provide useful diagnostic information in patients suffering from endometrial thickening and abnormal bleeding of unknown etiology.

Benign endometrial changes are the most common observed pathological findings in the endometrial samplings of reproductive-age women with abnormal uterine bleeding. However, endometrial polyps, endometrial hyperplasia, and submucosal fibroids are also frequently encountered. ${ }^{15,16}$ In recent years, the number of diagnostic tests in clinical practice has increased rapidly. The sensitivity of transvaginal ultrasound which is a practical method for the detection of endometrial pathologies, is reported as $50 \%$ and the specificity as $90 \% .{ }^{17}$ However, the unsuccessful diagnostic role of TV ultrasound in endometrial pathologies is also shown by many studies. ${ }^{18,19}$ Failure to diagnose with the ultrasonography results directs gynecologists to invasive procedures and raises the need for pathological diagnosis.

Patients admitted with abnormal bleeding who show increased endometrial thickness $(>12 \mathrm{~mm})$ and irregularity are often referred for invasive diagnostic procedures such as curettage, saline infusion sonography (SIS) and hysteroscopy instead of ultrasound. Especially in patients with a suspected diagnosis of submucosal fibroids or endometrial polyps, the success of hysteroscopy on the diagnosis has been shown to be between $53-97 \%{ }^{20,21}$

Hysteroscopic myomectomy should be considered firstline conservative surgical therapy for the management of symptomatic submucosal myomas. ${ }^{22}$ It is highly effective in resolving abnormal bleeding, with a success rate between 70 $90 \%$. In addition, it reverses the negative impacts of submucosal fibroids on fertility (both in the case of spontaneous fertility and in assisted reproduction technologies). However, due to the lack of equipment, invasiveness of the procedure, and cost, hysteroscopy is typically not the preferred modality of treatment, and physicians may instead opt for fractional curettage. However, for both of these procedures, knowledge of fibroid characteristics prior to surgery helps to select the appropriate treatment, as well as to ensure that the appropriate instruments and surgical expertise are in place.

Patients who are admitted with abnormal uterine bleeding but do not show the pathognomonic characteristics of a submucosal fibroid or a polyp on transvaginal sonography may be candidates for more invasive procedures such as curettage or hysteroscopy. The use of platelet counts and MPV as diagnostic tools may help reduce the use of invasive procedures when they are not required or to select the most appropriate invasive procedure for follow-up. Because of its accessibility, simplicity, low cost, and high sensitivity, MPV may be a highly valuable tool in distinguishing submucosal fibroids from other causes of abnormal uterine bleeding. However, additional larger prospective studies are required to confirm these findings and to clarify a rigorous diagnostic guideline.

\section{References}

1. Tsai MC, Goldstein SR. Office diagnosis and management of abnormal uterine bleeding. Clin Obstet Gynecol 2012; 55:635-50.

2. Emanuel MH. New developments in hysteroscopy. Best Pract Res Clin Obstet Gynaecol 2013;27:421-9

3. Munro MG, Critchley HO, Broder MS et al. FIGO Working Group on Menstrual Disorders. FIGO classification system (PALM-COEIN) for causes of abnormal uterine bleeding in nongravid women of reproductive age. Int J Gynaecol Obstet 2011;113:3-13.

4. Taylor PJ. Hysteroscopy: where have we been, where are we going? J Reprod Med 1993;38:757-62.

5. Molloy D, Crosdale S. National trends in gynaecological endoscopic surgery. Aust N Z J Obstet Gynaecol 1996; $36: 27-31$

6. Bettochi S, Nappi L, Ceci O, Selvaggi L. Office hysteroscopy. Obstet Gynecol Clin North America 2004; 3:641-54.

7. Incebıyık A, Seker A, Vural M, Hilali NG, Camuzcuoglu A, Camuzcuoglu H. May mean platelet volume levels be a predictor in the diagnosis of pelvic inflammatory disease? Wien Klin Wochenschr 2014;126:422-6

8. Yildirim MA, Seckin KD, Togrul C, et al. Roles of neutrophil/lymphocyte and platelet/lymphocyte ratios in the early diagnosis of malignant ovarian masses 2014;15: 6881-5.

9. Liang M, Wang H, Zhang Y, Lu S, Wang Z. Expression and functional analysis of platelet-derived growth factor in uterine leiomyomata. Cancer Biology \& Therapy 2006; 5:28-33. 
10. Suo G, Jiang Y, Cowan B, Wang J. Platelet-Derived growth factor $\mathrm{C}$ is upregulated in human uterine fibroids and regulates uterine smooth muscle cell growth. Biology of Reproduction 2009;81:749-58

11. Cramer SF, Horiszny JA, Leppert P. Epidemiology of uterine leiomyomas. With an etiologic hypothesis. J Reprod Med 1995;40:595-600.

12. Asano R, Asai-Sato M, Miyagi Y, et al. Aberrant expression of erythropoietin in uterine leiomyoma: implications in tumor growth. Am J Obstet Gynecol 2015;213(2):199 e1-8

13. Wolf RF, Peng J, Friese P, Gilmore LS, Burstein SA, Dale GL. Erythropoietin administration increases production and reactivity of platelets in dogs. Thromb Haemost 1997;78:1505-9.

14. McDonald TP, Cottrell MB, Clift RE, Cullen WC, Lin FK. High doses of recombinant erythropoietin stimulate platelet production in mice. Exp Hematol 1987;15:719-21.

15. De Wit AC, Vleugels MP, de Kruif JH. Diagnostic hysteroscopy: a valuable diagnostic tool in the diagnosis of structural intra-cavital pathology and endometrial hyperplasia or carcinoma? Six years of experience with nonclinical diagnostic hysteroscopy. Eur J Obstet Gynecol Reprod Biol 2003;110:79-82.

16. Guin G, Sandhu SK, Lele A, Khare S. Hysteroscopy in evaluation of abnormal uterine bleeding. J Obstet Gynaecol India 2011;61:546- 9.
17. Arslan S, Yüksel K, Samay ÖG, Yeşilyurt H, Yalçin H, Gökmen O. Office hysteroscopy versus transvaginal ultrasonography in the evaluation of patients with excessive uterine bleeding. Gynecol Obstet Reprod Med 2001;7:3640.

18. Gerber B, Krause A, Muller H, et al. Effects of adjuvant tamoxifen on the endometrium in postmenopausal women with breast cancer: a prospective long-term study using transvaginal ultrasound. 2000;18:3459-63

19. Garuti G, Grossi F, Cellani F, Centinaio G, Colonelli M, Leurti M. Hysteroscopic assessment of menopausal breast-cancer patients taking tamoxifen; there is a bias from the mode of endometrial sampling in estimating endometrial morbidity. Breast Cancer Res Treat 2002;72: 245-53

20. Sheikh M, Sawhney S, Khurana A, Al-Yatama M. Alteration of sonographic texture of the endometrium in post-menopausal bleeding. A guide to further management. Acta Obstet Gynecol Scand 2000;79:1006-10.

21. Randelzhofer B, Prompeler HJ, Sauerbrei W, Madjar H, Emons G. Value of sonomorphological criteria of the endometrium in women with postmenopausal bleeding: a multivariate analysis. Ultrasound Obstet Gynecol 2002; 19:62-8.

22. Vilos GA, Allaire C, Laberge PY, Leyland N. The management of uterine leiomyomas. J Obstet Gynaecol Can 2015;37:157-81. 